\title{
The aortic root does not dilate over time after replacement of the aortic valve and ascending aorta in patients with bicuspid or tricuspid aortic valves
}

\author{
Sonya K. Hui, PhD, ${ }^{a}$ Chun-Po Steve Fan, PhD, ${ }^{\mathrm{b}}$ Shakira Christie, BSc, ${ }^{\mathrm{b}}$ Christopher M. Feindel, MD, MSc, ${ }^{\mathrm{b}}$ \\ Tirone E. David, MD, ${ }^{b}$ and Maral Ouzounian, $\mathrm{MD}, \mathrm{PhD}^{\mathrm{b}}$
}

\section{ABSTRACT}

Objective: Whether the aortopathy associated with bicuspid aortic valve (BAV) disease occurs secondary to genetic or hemodynamic factors remains controversial. In this article we describe the natural history of the aortic root in patients with bicuspid versus tricuspid aortic valves (TAVs) after replacement of the aortic valve and ascending aorta.

Methods: From 1990 to 2010, 406 patients (269 BAV, 137 TAV) underwent aortic valve and ascending aorta replacement at a single institution. Patients with aortic dissection, endocarditis, previous aortic surgery, or Marfan syndrome were excluded. All available follow-up imaging was reviewed.

Results: Mean imaging follow-up was $5.5( \pm 5.3)$ years. Of all patients, $66.5 \%$ had at least 1 aortic root measurement after the index operation. Baseline aortic diameter was comparable between groups. In patients with BAV, aortic root diameter increased at a clinically negligible rate over time $(0.654 \mathrm{~mm}$ per year; $95 \%$ confidence interval, $0.291-1.016 ; P<.001)$, similar to patients with TAV $(P=.92)$. Mean clinical follow-up was $8.1( \pm 5.4)$ years. During follow-up, 18 patients underwent reoperation, $89 \%$ for a degenerated bioprosthetic aortic valve. Only 1 patient underwent reoperation for a primary indication of aortic aneurysmal disease, 22 years after the index operation. There were no differences in cumulative incidence rates of aortic reoperation $(P=.14)$ between patients with BAV and TAV.

Conclusions: Mid-term imaging after aortic valve and ascending aorta replacement indicates that if the aortic root is not dilated at the time of surgery, the risk of enlargement over time is minimal, negating the need for prophylactic root replacement in patients with BAV or TAV. ( $J$ Thorac Cardiovasc Surg 2018;156:5-13)

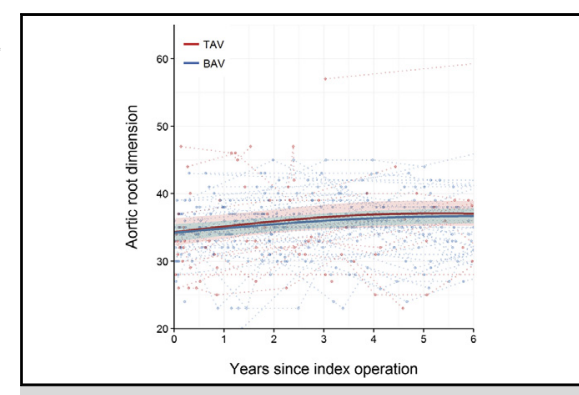

Aortic root diameter over time after aortic valve and ascending aorta replacement.

\section{Central Message}

In patients requiring replacement of the aortic valve and ascending aorta, risk of enlargemen of the remaining aortic root over time is minimal, negating the need for prophylactic root replacement.

\section{Perspective}

Whether the aortopathy associated with bicuspid aortic valve disease occurs due to genetic or hemodynamic factors remains controversial. This work represents one of the largest natural history studies to date assessing aortic root dimensions with follow-up imaging data and reports minimal enlargement of the sinus segments after replacement of the aortic valve and ascending aorta.

See Editorial Commentaries pages 14 and 16.

See Editorial page 1.

\footnotetext{
From the a Michael G. DeGroote School of Medicine, Faculty of Health Sciences, McMaster University, Hamilton, Ontario, Canada; and ${ }^{\mathrm{b}}$ Division of Cardiovascular Surgery, Department of Surgery, Peter Munk Cardiac Centre, Toronto General Hospital, University of Toronto, Toronto, Ontario, Canada.

Read at the 97th Annual Meeting of The American Association for Thoracic Surgery, Boston, Massachusetts, April 29-May 3, 2017.

Received for publication April 17, 2017; revisions received Feb 6, 2018; accepted for publication Feb 25, 2018; available ahead of print April 12, 2018.

Address for reprints: Maral Ouzounian, MD, PhD, Toronto General Hospital, 200 Elizabeth St, 4N-464, Toronto, Ontario M5G2C4, Canada (E-mail: maral. ouzounian@uhn.ca).

$0022-5223 / \$ 36.00$

Copyright (c) 2018 by The American Association for Thoracic Surgery

https://doi.org/10.1016/j.jtcvs.2018.02.094
}

Bicuspid aortic valve (BAV) disease is the most common congenital cardiac abnormality, occurring in approximately $1 \%$ to $2 \%$ of the general population. ${ }^{1}$ Patients with BAV might develop significant valvular dysfunction, with as many as $50 \%$ of patients requiring surgical aortic valve

Uf Scanning this QR code will
take you to the supplemental
$\begin{aligned} & \text { video and tables for this } \\ & \text { article. }\end{aligned}$



Abbreviations and Acronyms
AVR $=$ aortic valve replacement
$\mathrm{BAV}=$ bicuspid aortic valve
$\mathrm{CI}=$ confidence interval
$\mathrm{CT}=$ computed tomography
$\mathrm{HR}=$ hazard ratio
MRI $=$ magnetic resonance imaging
$\mathrm{RAA}=$ replacement of the ascending aorta
$\mathrm{TAV}=$ tricuspid aortic valve

replacement (AVR). ${ }^{2}$ In addition to pathology of the aortic valve, patients with BAV are 86 times more likely to have proximal aortic aneurysms and 8 times more likely to experience aortic dissection compared with the general population. ${ }^{3}$ Aortopathy is estimated to occur in $50 \%$ of patients with BAV and progresses with age, affecting as many as $88 \%$ to $91 \%$ of patients over 50 to 60 years. ${ }^{1}$ There are competing hemodynamic versus genetic theories regarding the pathogenesis of aortic dilatation in patients with $\mathrm{BAV}^{4-7}$ Although genetic as well as hemodynamic factors are known to contribute to the heterogeneity of BAV aortopathy, there is no consensus about their degree of involvement, interaction, and implications for surgical guidelines.

Natural history data reporting aortic root dilatation in patients with BAV after surgical AVR and ascending aorta (RAA) is lacking, and is necessary to clarify BAV aortopathy progression. ${ }^{8}$ If the risk of aortic root enlargement or of aortic complications is minimal in this cohort over time, this might negate the need for a prophylactic root replacement procedure in these patients. In this retrospective study we describe the natural history of the aortic root after AVR and RAA in patients with BAV compared with patients with tricuspid aortic valve (TAV).

\section{METHODS \\ Study Population}

All patients who underwent first-time combined AVR and RAA at the Peter Munk Cardiac Centre from January 1990 to December 2010 were identified through the cardiovascular surgery database. Patients underwent a full root replacement if the aortic root dimensions exceeded a diameter of $45 \mathrm{~mm}$ at the time of surgery. Approximately one-third of study patients also underwent replacement of the noncoronary sinus at the time of AVR and RAA. Indications for replacement of the noncoronary sinus at our institution include asymmetric dilatation of the noncoronary sinus, in particular older patients and those with BAVs without cephalad displacement of the coronary arteries or annuloaortic ectasia. In the early study period, sinus measurements were generally obtained in the long-axis view of aortic root using echocardiography. More recently, gated computed tomography (CT) imaging with sinus-to-sinus (3) and sinus-to-commissure (3) measurements have been used. The largest diameter of the 6 measurements is used to assess root size. However, intraoperative assessment of asymmetry and quality of the tissues also determine whether full root or partial root repair was performed. Isolated replacement of the noncoronary sinus with a patch was also used to facilitate the insertion of a larger prosthesis in patients with a small aortic annulus by permitting supra-annular placement of the valve. During the study period, 1660 patients underwent a full root replacement at our institution. Patients were grouped as either "hemiarch" or "RAA" to denote the extent and method of proximal aortic replacement (ie, either the ascending aorta was replaced under a period of circulatory arrest with hypothermia with or without cerebral perfusion (hemi-arch), or the cross-clamp was left in place during RAA). We excluded patients with aortic dissection, active endocarditis, connective tissue disorders (Marfan syndrome, Loeys-Dietz syndrome, etc), and those who underwent the Ross procedure (Figure 1).

\section{Data Collection and Definitions}

Perioperative clinical data were prospectively collected on all patients who underwent cardiac surgery in our institutional database. Operative reports were reviewed to confirm BAV status and cusp fusion type. Patients were contacted via phone or electronically to determine morbid outcomes and to confirm vital status. Imaging data were collected from all available echocardiography, CT, and magnetic resonance imaging (MRI) reports at baseline and during follow-up. Patients' community cardiologists were contacted to obtain clinical follow-up and imaging data. All available aortic root and arch dimension data were collected and analyzed. The Research Ethics Board of the University Health Network approved the study (REB 15-9164) and waived the need for individual patient consent.

\section{Statistical Analysis}

Descriptive analysis. Clinical characteristics were summarized in terms of medians (interquartile ranges) for continuous variable and frequencies for dichotomous and polytomous variables. Between-group differences in continuous variables were assessed using Wilcoxon rank-sum tests, and differences in dichotomous/polytomous variables were assessed using Fisher exact tests.

Longitudinal image analysis. We considered all available imaging data (MRI, CT, and echocardiography) collected longitudinally after the index operation and analyzed the imaging data using generalized least square methods. The breakdown of imaging data according to modality is reported in Table E1. The outcome variables were root dimension over time. The independent variables of interest included the cohort variable (BAV vs TAV), time of the imaging study (measured according to years since the index operation), and their interactions. We also considered age, sex, body surface area, and baseline aortic root dimension immediately after the index operation as control variables. Because of the small number of patients with serial imaging data, we were unable to account for other clinical variables. To account for the longitudinal nature of the data and irregular measurement times, we assumed each subject's root dimensions follow a multivariate normal distribution with a compound symmetry covariance structure. We modeled the progression of root dimension nonparametrically using restricted regression spline. The $95 \%$ confidence intervals (CIs) and $P$ values were calculated using Rubin's rule to combine regression results from multiple imputed data sets.

Multivariate analysis. Postoperative mortality was analyzed using multivariable Cox regression, stratified according to the period of the index operation (1995 or before, 1996-2000, 2001-2005, 2006-2010). Clinical risk factors and operative information were considered in the regression model. Risk factor analysis was conducted using stepwise variable selection on the basis of Akaike information criteria. All predictors, except the cohort variable, were subject to variable selection. To assess the reliability of the stepwise variable selection, the bootstrap method was used. Aortic reoperation was analyzed using cause-specific hazard regression models, stratified according to the year of the index operation. Because of the small number of patients with aortic reoperation, the regression 


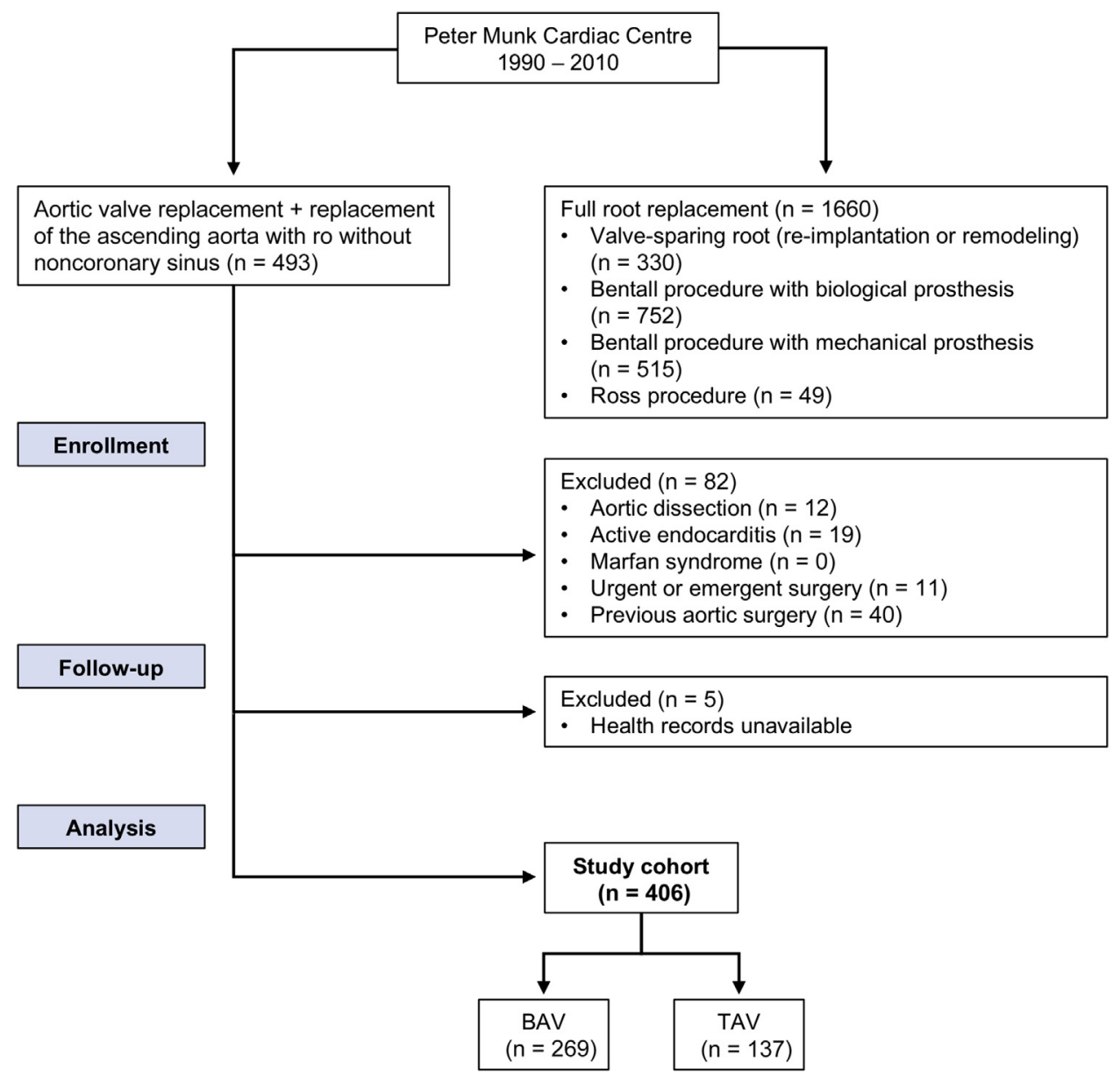

FIGURE 1. Consolidated Standards of Reporting Trials flow diagram showing reasons for exclusion from the study. BAV, Bicuspid aortic valve; $T A V$, tricuspid aortic valve.

models for reoperation included only age and sex, and no risk factor analysis was conducted. Analyses were conducted using $\mathrm{R}$ version 3.3.2 (https://www.r-project.org).

\section{RESULTS}

\section{Baseline Characteristics}

From 1990 to 2010, 406 patients were identified who underwent first-time replacement of their aortic valve and ascending aorta at the Peter Munk Cardiac Centre. The baseline characteristics of the final study cohort are shown in Table 1. Among this cohort, 269 patients $(66.3 \%)$ had BAV and 137 patients $(33.7 \%)$ had TAV. The mean age of the cohort was 66 (58-73) years and $69.2 \%$ were male. Most patients $(62.1 \%)$ had aortic stenosis at the time of surgery and most $(64.3 \%)$ received a bioprosthetic aortic valve. The overall mean size of the ascending aorta at the time of index operation was $46 \pm 7 \mathrm{~mm}$. In addition to AVR and RAA, 43.1\% of the patients in the study also underwent surgical replacement of the proximal arch under circulatory arrest during the index operation.
As expected, patients with BAV were significantly younger than those with TAV (BAV: 65 [range, 55-71] vs TAV: 70 [range, 65-76] years; $P<.001$ ) and more were male (BAV: $74.7 \%$ vs TAV: $58.4 \% ; P<.001$ ). More patients with BAV had replacement of the noncoronary sinus at the time of surgery (BAV: $36.1 \%$ vs TAV $19.7 \%$; $P<.001$ ), but fewer underwent use of circulatory arrest for an open distal anastomosis (BAV: $38.3 \%$ vs TAV $52.6 \% ; P<.001)$. Operative details and early outcomes are summarized in Tables 2 and 3.

\section{Aortic Root Imaging}

The mean follow-up time for the imaging studies was $5.5 \pm 5.3$ years and the maximum follow-up was 19.8 years. The baseline aortic root diameter was comparable between groups (BAV: $33 \pm 5 \mathrm{~mm}$, TAV: $32 \pm 6 \mathrm{~mm} ; P=.41$ ). Of the BAV patients, $70.6 \%$ and of the TAV patients, $58.4 \%$ had at least 1 measurement of the root after the index operation. Statistical analysis of all available imaging reports (echocardiogram, CT, and MRI) revealed that in patients with $\mathrm{BAV}$, the aortic root diameter increased at a small but 
TABLE 1. Baseline clinical characteristics of patients who underwent replacement of the aortic valve and ascending aorta

\begin{tabular}{lccc}
\hline \multicolumn{1}{c}{ Variable } & $\begin{array}{c}\text { BAV } \\
(\mathbf{n = 2 6 9 )}\end{array}$ & $\begin{array}{c}\text { TAV } \\
(\mathbf{n}=\mathbf{1 3 7})\end{array}$ & $\begin{array}{c}\boldsymbol{P} \\
\text { value }\end{array}$ \\
\hline Median age (IQR), y & $65(55-71)$ & $70(65-76)$ & $<.001$ \\
Male sex & $201(74.7)$ & $80(58.4)$ & $<.001$ \\
\hline Diabetes & $27(10.0)$ & $12(8.8)$ & .73 \\
Hypertension & $124(46.1)$ & $82(59.9)$ & .01 \\
Hyperlipidemia & $106(39.8)$ & $53(38.7)$ & .65 \\
Timing of surgery & & & .04 \\
$\quad$ Elective & $236(87.7)$ & $109(79.6)$ & \\
$\quad$ Urgent & $33(12.3)$ & $28(20.4)$ & \\
Any previous cardiac surgery & $9(3.3)$ & $6(4.4)$ & .59 \\
Recent myocardial infarction & $3(1.1)$ & $1(0.7)$ & 1.00 \\
Renal failure & $1(0.4)$ & $1(0.7)$ & 1.00 \\
New York Heart Association & & & $<.001$ \\
$\quad$ class & & & \\
I & $54(20.1)$ & $11(8.1)$ & \\
II & $98(36.6)$ & $39(28.7)$ & \\
III & $89(33.2)$ & $53(39.0)$ & \\
IV & $27(10.1)$ & $33(24.3)$ & \\
\hline
\end{tabular}

Left ventricular ejection

fraction

$>60 \%$

$40 \%$ to $59 \%$

$20 \%$ to $39 \%$

$<20 \%$

$174(64.7)$

$66(24.5)$

67 (48.9)

$24(8.9)$

5 (1.9)

$48(35.0)$

$19(13.9)$

$3(2.2)$

\begin{tabular}{lccc} 
Congestive heart failure & $65(24.3)$ & $71(51.8)$ & $<.001$ \\
\hline Syncope & $17(6.3)$ & $7(5.1)$ & .88 \\
Current or former smoker & $160(59.5)$ & $83(60.6)$ & .91 \\
$\begin{array}{l}\text { Chronic obstructive } \\
\quad \text { pulmonary disease }\end{array}$ & $7(2.6)$ & $7(5.1)$ & .25 \\
$\begin{array}{l}\text { Previous stroke or transient } \\
\quad \text { ischemic attack }\end{array}$ & $22(8.2)$ & $20(14.6)$ & .06 \\
$\begin{array}{l}\text { Aortic valve disease } \\
\quad \text { Stenosis }\end{array}$ & $189(70.3)$ & $63(46.0)$ & \\
$\quad$ Regurgitation & $31(11.5)$ & $43(31.4)$ & \\
$\quad$ Mixed & $42(15.6)$ & $30(21.9)$ & \\
$\quad$ None & $6(2.2)$ & $0(0.0)$ & \\
\hline
\end{tabular}

Data are presented as $\mathrm{n}(\%)$ except where otherwise noted. $B A V$, Bicuspid aortic valve; $T A V$, tricuspid aortic valve; $I Q R$, interquartile range.

clinically negligible rate over time $(0.654 \mathrm{~mm}$ per year $95 \%$ CI, 0.291-1.016; $P<.001)$, which was not different compared with patients with TAV $(P=.92$; Figure 2$)$. Baseline aortic root diameter did not significantly affect growth, assessed using the generalized least squares model and according to interaction with growth rate $(P=.34)$.

\section{Aortic Arch Imaging}

Baseline aortic arch diameter was comparable between groups (BAV: $31 \pm 8 \mathrm{~mm}$; TAV: $32 \pm 5 \mathrm{~mm} ; P=.46$ ). There were 75 (BAV: 50, TAV: 25) patients with at least 1 measurement of the aortic arch after the index operation. The aortic arch dimension at last known follow-up was similar between groups (BAV: $30 \pm 5 \mathrm{~mm}$ vs TAV: $30 \pm 7 \mathrm{~mm} ; P=.89$ ) and was not different between those who had undergone aortic replacement with a cross-clamp in place or under circulatory arrest (RAA: $30 \pm 5 \mathrm{~mm}$ vs hemi-arch: $30 \pm 6 \mathrm{~mm} ; P=.93$ ).

\section{Mid-Term Outcomes}

Follow-up was complete (until 2013 to 2015 or death) for 316 patients $(77.8 \%)$. The mean (SD) follow-up time was $8.1 \pm 5.4$ years amounting to 3278.9 patient-years. After adjusting for baseline characteristics, patients with BAV had a similar risk of long-term mortality compared with those with TAV (hazard ratio [HR], 0.74; 95\% CI, 0.49-1.12; $P=.16$ ).

During the follow-up period, 18 (BAV: 13, TAV: 5) patients underwent a cardiac reoperation, most of which $(89 \%)$ were for a degenerated bioprosthetic aortic valve (Table E2). At the time of cardiac reoperation, 10 patients had their aortic root replaced and 2 also had their arch replaced. Of the 406 patients in the study cohort, only 1 patient underwent a cardiac reoperation for a primary indication of aortic aneurysmal disease 22 years after the index operation. There were no differences in cumulative incidence rates of cardiac $(P=.37)$ or aortic reoperation $(P=.14)$ between patients with BAV and TAV (Figure 3). After adjusting for age and sex, the risk of any cardiovascular reoperation (HR, $0.29 ; P=.62)$ or any aortic reoperation (HR, $0.88 ; P=.27$ ) was similar in both groups.

\section{DISCUSSION}

Development and progression of aortopathy in patients with BAV is likely because of a combination of hemodynamic and genetic factors. ${ }^{4-6} \mathrm{~A}$ genetic basis for BAV aortopathy ${ }^{9,10}$ and progressive enlargement of the aorta after AVR has been observed. ${ }^{11}$ A study analyzing longterm outcomes in patients who underwent BAV surgery suggests that an aortic diameter $>4.5 \mathrm{~cm}$ or cross-sectional area-to-height ratio $>8$ is associated with ascending aortic events, meriting surgical repair. ${ }^{12}$ Although guidelines have recently increased the size threshold for prophylactic aortic repair in $\mathrm{BAV},{ }^{13-15}$ some groups advocate for aggressive replacement of the aortic root and proximal arch in patients with BAV who present with aortic valve disease and aneurysms limited to the ascending aorta. ${ }^{16-18}$

Conversely, other studies show no dilatation of the aortic root or ascending aorta after AVR in patients with BAV compared with patients with TAV or the general population. ${ }^{19-21}$ Itagaki et al showed that patients with BAV develop significantly less aortic dilatation after AVR compared with patients with Marfan syndrome. ${ }^{22}$ These reports suggest that replacement of the diseased bicuspid valve might prevent future aortic disease by treating hemodynamic factors, negating the need for prophylactic 
TABLE 2. Intraoperative details

\begin{tabular}{|c|c|c|c|c|c|}
\hline Variable & $\mathbf{N}$ & BAV $(n=269)$ & $\mathbf{N}$ & TAV $(\mathbf{n}=137)$ & $P$ value \\
\hline Size of aortic prosthesis, mean $\pm \mathrm{SD}, \mathrm{mm}$ & 269 & $25 \pm 2$ & 137 & $24 \pm 2$ & $<.001$ \\
\hline Size of aortic prosthesis, $\mathrm{mm}$ & 269 & & 137 & & $<.001$ \\
\hline 19 & & $0(0.0)$ & & $1(0.7)$ & \\
\hline 21 & & $7(2.6)$ & & $22(16.1)$ & \\
\hline 23 & & $61(22.7)$ & & $49(35.8)$ & \\
\hline 25 & & $98(36.4)$ & & $41(29.9)$ & \\
\hline 27 & & $87(32.3)$ & & $20(14.6)$ & \\
\hline 29 & & $16(5.9)$ & & $4(2.9)$ & \\
\hline Noncoronary sinus replacement & 269 & $97(36.1)$ & 137 & $27(19.7)$ & $<.001$ \\
\hline Extent of ascending aorta replacement & 263 & & 125 & & $<.001$ \\
\hline RAA & & $160(59.5)$ & & $53(38.7)$ & \\
\hline Hemi-arch & & $103(38.3)$ & & $72(52.6)$ & \\
\hline Type of prosthesis & 269 & & 137 & & .05 \\
\hline Carpentier-Edwards pericardial & & $39(14.5)$ & & $35(25.5)$ & \\
\hline Hancock II Porcine & & $109(40.5)$ & & $44(32.1)$ & \\
\hline Mosaic & & $20(7.4)$ & & $14(10.2)$ & \\
\hline St Jude & & $56(20.8)$ & & $27(19.7)$ & \\
\hline Other & & 45 (16.7) & & $17(12.4)$ & \\
\hline Mitral valve repair/replacement & 269 & $17(6.3)$ & 137 & $21(15.3)$ & .006 \\
\hline Tricuspid valve repair & 269 & $0(0.0)$ & 137 & $6(4.4)$ & N/A \\
\hline Median cardiopulmonary bypass time (IQR), min & 269 & $105(78-132)$ & 137 & $113(88-145)$ & $<.001$ \\
\hline Median cross-clamp time (IQR), min & 269 & $80(57-104)$ & 137 & $87(65-114)$ & $<.001$ \\
\hline Median circulatory arrest (IQR), min & 93 & $15(12-19)$ & 69 & $16(12-21)$ & .13 \\
\hline Concomitant coronary bypass & 269 & & 137 & & .002 \\
\hline 1 & & $37(13.8)$ & & $28(20.4)$ & \\
\hline 2 or more & & $48(17.8)$ & & $40(29.2)$ & \\
\hline BAV fusion type & 91 & & & & \\
\hline RL & & $52(57.1)$ & & & \\
\hline $\mathrm{RN}$ & & $35(38.5)$ & & & \\
\hline LN & & $4(4.4)$ & & & \\
\hline
\end{tabular}

Data are presented as n (\%) except where otherwise noted. Prostheses are from the following manufacturers: Carpentier-Edwards pericardial: Carpentier-Edwards (Irvine, Calif), Hancock II Porcine and Mosaic: Medtronic (Dublin, Ireland), and St Jude: St Jude Medical (St Paul, Minn). BAV, Bicuspid aortic valve; TAV, tricuspid aortic valve; SD, standard deviaiton; $R A A$, replacement of the ascending aorta; $N / A$, not applicable; $I Q R$, interquartile range; $R L$, right-left coronary cusp fusion; $R N$, right and noncoronary cusp fusion; $L N$, left and noncoronary cusp fusion.

resection of the aorta. An important limitation of these studies was that patients with BAV did not have known aortopathy at the time of surgery.

Natural history data on the aortic root in patients with BAV have been limited. Park and colleagues showed very low rates of aortic reoperation and no enlargement of the aortic root in patients with BAV after AVR and RAA. However, this was on the basis of limited echocardiography data from a small cohort of patients $(n=34)$ with a mean followup of 3.3 years. $^{23}$ This investigation had a significantly larger sample size of imaging data and incorporated imaging at multiple time points over the follow-up period. Our findings of a negligible growth rate of the aortic root in patients with BAV are supported by other recent studies with comparable observations. $^{24,25}$ Considering the mean age of the patients in this study, neither patients with BAV nor TAV are likely to require surgical intervention for aortic root aneurysm after AVR and RAA. Overall, these data support the current surgical strategy and indicate that patients might not need prophylactic replacement of a nonaneurysmal aortic root.

It should be noted that the management of the aortic root is complex and includes the consideration of several factors other than absolute aortic dimensions. Additional determinants include the patient's age and comorbidities, degree and rate of root dilatation, number of sinuses involved, cephalad displacement of the coronary ostia, quality of aortic tissue, patient preference for tissue or mechanical valve, surgical proficiency with root replacement procedures, need for concomitant coronary bypass grafting or complex arch reconstruction, and likelihood of redo cardiac surgery or transcatheter valve-in-valve AVR in the future. ${ }^{26}$ These factors all influence a surgeon's decision regarding how much, if any, of the aortic root should be replaced. 
TABLE 3. Early outcomes

\begin{tabular}{lccc}
\hline \multicolumn{1}{c}{ Variable } & $\begin{array}{c}\text { BAV } \\
(\mathbf{n}=\mathbf{2 6 9})\end{array}$ & $\begin{array}{c}\text { TAV } \\
(\mathbf{n}=\mathbf{1 3 7})\end{array}$ & $\boldsymbol{P}$ value \\
\hline Mortality & $5(1.9)$ & $7(5.1)$ & .12 \\
Reoperation for bleeding & $29(10.8)$ & $19(13.9)$ & .42 \\
\hline Perioperative myocardial infarction & $2(0.7)$ & $1(0.7)$ & 1.00 \\
Insertion of permanent pacemaker & $14(5.2)$ & $13(9.5)$ & .14 \\
\hline Post-operative atrial fibrillation & $78(32.1)$ & $43(38.4)$ & .03 \\
Stroke or transient ischemic attack & $2(0.7)$ & $3(2.2)$ & .34 \\
Sternal wound infection & $4(1.5)$ & $5(3.6)$ & .28 \\
\hline Sepsis & $7(2.6)$ & $6(4.4)$ & .38 \\
\hline
\end{tabular}

Data are presented as $\mathrm{n}(\%)$ except where otherwise noted. $B A V$, Bicuspid aortic valve; $T A V$, tricuspid aortic valve.

The aortic arch might also become aneurysmal in patients with $\mathrm{BAV},{ }^{27}$ leading some groups to recommend replacing the proximal arch under circulatory arrest prophylactically in patients with BAV undergoing RAA. ${ }^{28}$ Park et al showed no significant difference in arch diameter using echocardiography in patients with BAV after AVR or RAA in 58 patients with a median follow-up time of 4 years. ${ }^{29}$ A study by Abdulkareem et al showed no significant dilatation of the arch after RAA in patients with BAV compared with patients with TAV at 5 years after the index operation. ${ }^{19}$

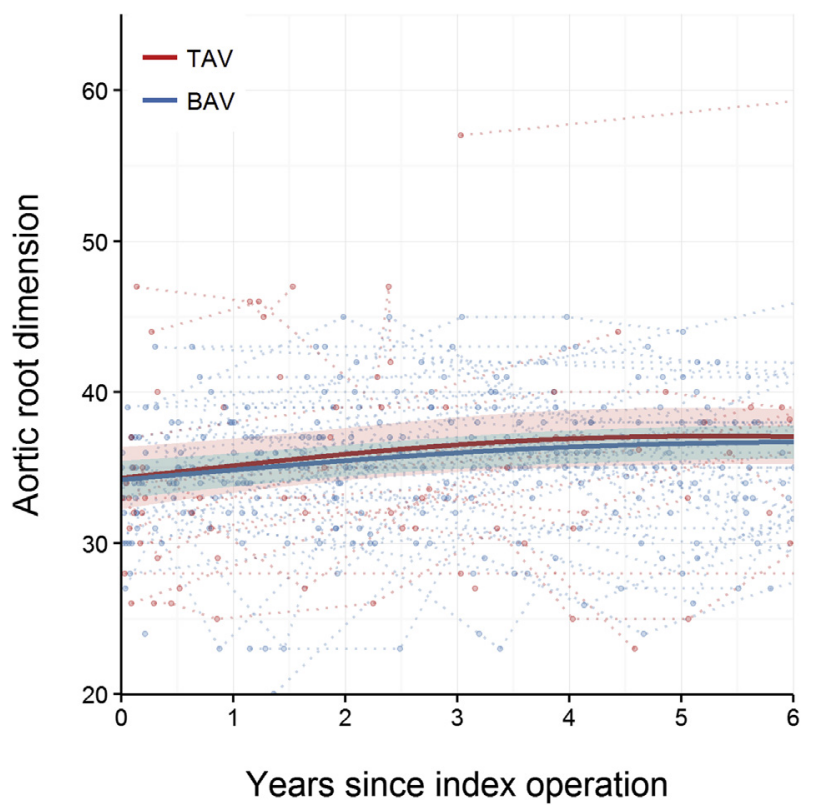

FIGURE 2. Aortic root diameter over time in patients with aortic valve and ascending aorta replacement. Using the generalized least squared method, it was observed that the aortic root increased by $0.6554 \mathrm{~mm}$ per year $(95 \%$ CI, 0.291-1.016; $P<.001)$ in patients with BAV and by $0.825 \mathrm{~mm}$ per year $(95 \% \mathrm{CI}, 0.181-1.469 ; P=.012)$ in patients with TAV. The differential progression rate between patients with BAV and TAV (ie, the difference in the slopes) was not statistically significant $(P=.92)$. TAV, Tricuspid aortic valve; $B A V$, bicuspid aortic valve.

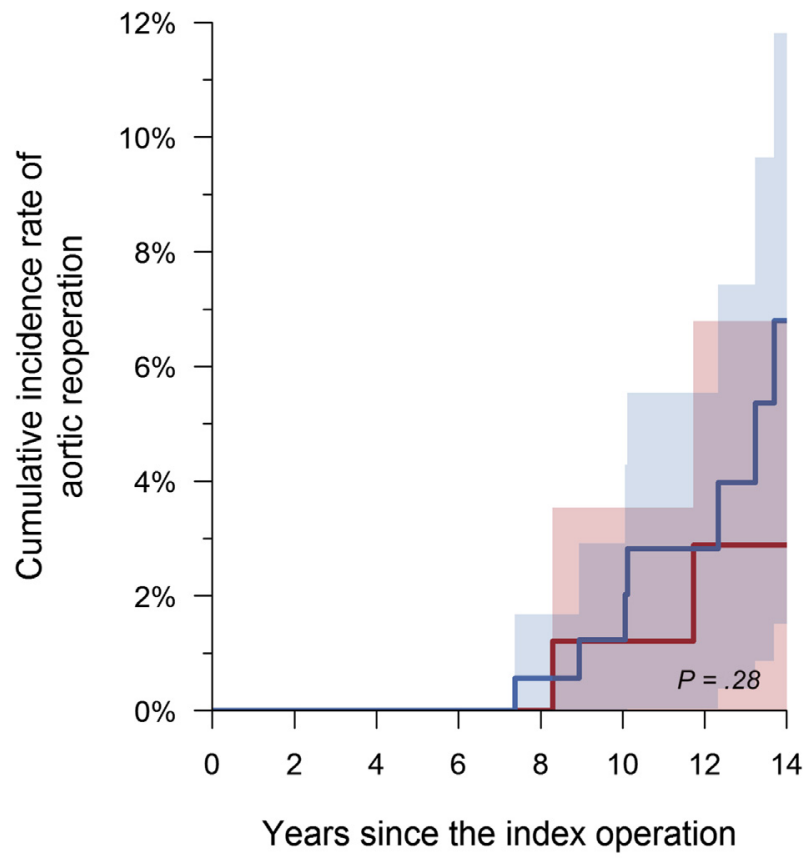

\section{At-risk: \\ TAV: $\begin{array}{llllllll}137 & 108 & 97 & 80 & 58 & 42 & 30 & 15\end{array}$ \\ BAV: $\begin{array}{llllllll}269 & 223 & 211 & 190 & 141 & 102 & 66 & 42\end{array}$}

FIGURE 3. Aortic reoperation over time in patients with aortic valve and ascending aorta replacement. The cumulative incidence rates of aortic reoperation were summarized. Gray's test was applied to assess differences between cohorts. There was no significant difference in cumulative incidence rates of aortic reoperation in patients with BAV compared with TAV $(P=.14) . T A V$, Tricuspid aortic valve; $B A V$, bicuspid aortic valve.

Accordingly, this study showed that arch diameter at last known follow-up was not different after AVR and RAA in patients with BAV compared with those with TAV. Furthermore, arch dimensions were not different between patients who underwent hemi-arch procedures and those who had a cross-clamp left in place during replacement of their ascending aorta clamp, supporting the current surgical approach to the arch.

\section{LIMITATION}

The main limitations of this study are the sample size and incomplete mid-term imaging follow-up. A prospectively designed study with complete imaging follow-up for a longer duration of time would provide more definitive data. Certain BAV fusion types are associated with different presentations of aortopathy. ${ }^{30-32}$ However, we did not have a large enough sample size to examine aortic size progression according to BAV fusion type. Similarly, most patients in our study had a stenotic aortic valve and we were unable to identify those with a root phenotype (annuloaortic ectasia and aortic insufficiency), who would be more at risk of an aortic root aneurysm. ${ }^{33,34}$ Last, arch measurements were reported at last known follow-up, 


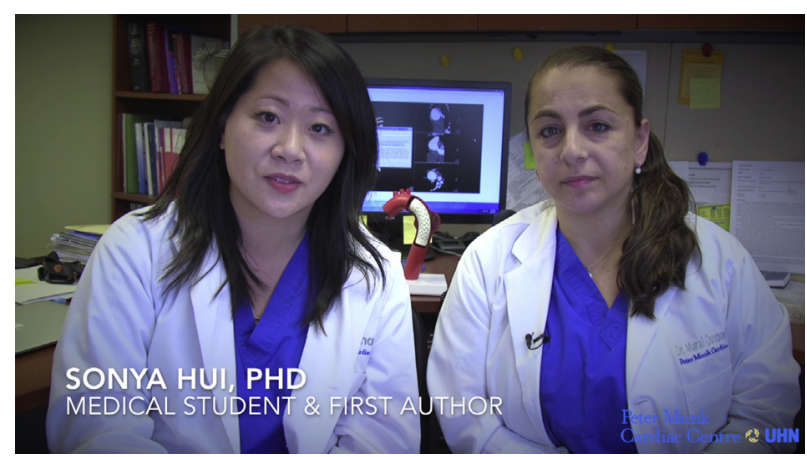

VIDEO 1. Significance of findings. The principal investigator and senior author Dr Maral Ouzounian and first author Sonya K. Hui explain the relevance and importance of the study results. Video available at: http://www. jtcvsonline.org/article/S0022-5223(18)30775-X/fulltext.

which is a different time point for each patient and therefore not directly comparable. The limited number of available arch measurements made it such that it was not possible to report a growth rate or arch measurements at a single time point. Baseline arch dimensions, however, were small and not different between groups and no patient experienced significant aneurysmal degeneration of the arch during the follow-up period. These observations should be considered preliminary until confirmed by larger studies with longer and more complete follow-up.

Our aortic measurements came from multiple imaging modalities and there might be systematic differences in how these are reported. Differences in measurements between imaging modalities is likely to have a minimal effect on our findings regarding the aortic root, because $98.5 \%$ of measurements were from echocardiography. The limited numbers of imaging measurements of the arch precluded meaningful statistical comparison according to modality. Additionally, imaging reports were from multiple institutions and the effect of interassessor variability was not formally assessed. A prospective study limited to a single imaging modality with a clearly specified location for aortic measurements and an interpreter blinded to patient groups would be ideal.

Finally, a significant proportion of our study cohort underwent surgical replacement of the noncoronary sinus as part of their index operation, which might have altered the natural progression of aortic root growth over time. Despite these limitations, this retrospective study constitutes the one of the most robust investigations to date to assess aortic root dimensions over time in patients with BAV after AVR and RAA.

\section{CONCLUSIONS}

The most important finding of this study is that in patients with normal root size after AVR for aortic stenosis with concomitant RAA with or without noncoronary sinus, mid-term imaging and clinical outcomes suggest the aortic root does not increase in size significantly over time in patients with either BAV or TAV (Video 1). Our study has validated the current surgical strategy of replacing frankly aneurysmal aortic tissue $(>45 \mathrm{~mm})$ at the time of AVR as a durable one. Prophylactically replacing the aortic root with normal dimensions or mild dilatation in patients with $\mathrm{BAV}$ or TAV for the theoretical risk of future sinus dilatation does not appear to be justified, because the risk of enlargement and aneurysm complications over time is minimal.

\section{Conflict of Interest Statement}

Authors have nothing to disclose with regard to commercial support.

The authors acknowledge statistical support from Kyle Runeckles.

\section{References}

1. Verma S, Siu SC. Aortic dilatation in patients with bicuspid aortic valve. N Engl J Med. 2014:370:1920-9.

2. Roberts WC, Ko JM. Frequency by decades of unicuspid, bicuspid, and tricuspid aortic valves in adults having isolated aortic valve replacement for aortic stenosis, with or without associated aortic regurgitation. Circulation. 2005;111:920-5.

3. Michelena HI, Khanna AD, Mahoney D, Margaryan E, Topilsky Y, Suri RM, et al. Incidence of aortic complications in patients with bicuspid aortic valves. JAMA. 2011;306:1104-12.

4. Girdauskas E, Borger MA, Secknus MA, Girdauskas G, Kuntze T. Is aortopathy in bicuspid aortic valve disease a congenital defect or a result of abnormal hemodynamics? A critical reappraisal of a one-sided argument. Eur J Cardiothorac Surg. 2011;39:809-14.

5. Barker AJ, Markl M, Burk J, Lorenz R, Bock J, Bauer S, et al. Bicuspid aortic valve is associated with altered wall shear stress in the ascending aorta. Circ Cardiovasc Imaging. 2012;5:457-66.

6. Hope MD, Sigovan M, Wrenn SJ, Saloner D, Dyverfeldt P. MRI hemodynamic markers of progressive bicuspid aortic valve-related aortic disease. J Magn Reson Imaging. 2014;40:140-5.

7. Masri A, Kalahasti V, Alkharabsheh S, Svensson LG, Sabik JF, Roselli EE, et al. Characteristics and long-term outcomes of contemporary patients with bicuspid aortic valves. J Thorac Cardiovasc Surg. 2016;151:1650-9.e1.

8. Sundt TM. Aortic replacement in the setting of bicuspid aortic valve: how big? How much? J Thorac Cardiovasc Surg. 2015;149:S6-9.

9. Biner S, Rafique AM, Ray I, Cuk O, Siegel RJ, Tolstrup K. Aortopathy is prevalent in relatives of bicuspid aortic valve patients. J Am Coll Cardiol. 2009;53: 2288-95.

10. Pepe G, Nistri S, Giusti B, Sticchi E, Attanasio M, Porciani C, et al. Identification of fibrillin 1 gene mutations in patients with bicuspid aortic valve (BAV) without Marfan syndrome. BMC Med Genet. 2014;15:23.

11. Yasuda H, Nakatani S, Stugaard M, Tsujita-Kuroda Y, Bando K, Kobayashi J, et al. Failure to prevent progressive dilation of ascending aorta by aortic valve replacement in patients with bicuspid aortic valve: comparison with tricuspid aortic valve. Circulation. 2003;108(Suppl 1):II291-4.

12. Svensson LG, Kim KH, Blackstone EH, Rajeswaran J, Gillinov AM, Mihaljevic T, et al. Bicuspid aortic valve surgery with proactive ascending aorta repair. J Thorac Cardiovasc Surg. 2011;142:622-9. 629.e1-3.

13. Nishimura RA, Otto CM, Bonow RO, Carabello BA, Erwin JP III, Guyton RA et al. 2014 AHA/ACC guideline for the management of patients with valvular heart disease: a report of the American College of Cardiology/American Heart Association task force on practice guidelines. Circulation. 2014;129:e521-643.

14. Erbel R, Aboyans V, Boileau C, Bossone E, Bartolomeo RD, Eggebrecht H, et al. 2014 ESC guidelines on the diagnosis and treatment of aortic diseases: document covering acute and chronic aortic diseases of the thoracic and abdominal aorta of the adult. The task force for the diagnosis and treatment of aortic diseases of the European Society of Cardiology (ESC). Eur Heart J. 2014;35:2873-926.

15. 2010 ACCF/AHA/AATS/ACR/ASA/SCA/SCAI/SIR/STS/SVM Guidelines for the Diagnosis and Management of Patients With Thoracic Aortic Disease Representative Members, Hiratzka LF, Creager MA, Isselbacher EM, Svensson LG, 
2014 AHA/ACC Guideline for the Management of Patients With Valvular Heart Disease Representative Members, et al. Surgery for aortic dilatation in patients with bicuspid aortic valves: a statement of clarification from the American College of Cardiology/American Heart Association task force on clinical practice guidelines. J Thorac Cardiovasc Surg. 2016;151:959-66.

16. Borger MA, Preston M, Ivanov J, Fedak PW, Davierwala P, Armstrong S, et al. Should the ascending aorta be replaced more frequently in patients with bicuspid aortic valve disease? J Thorac Cardiovasc Surg. 2004;128:677-83.

17. Nazer RI, Elhenawy AM, Fazel SS, Garrido-Olivares LE, Armstrong S, David TE. The influence of operative techniques on the outcomes of bicuspid aortic valve disease and aortic dilatation. Ann Thorac Surg. 2010;89:1918-24.

18. Etz CD, Homann TM, Silovitz D, Spielvogel D, Bodian CA, Luehr M, et al Long-term survival after the Bentall procedure in 206 patients with bicuspid aortic valve. Ann Thorac Surg. 2007;84:1186-93.

19. Abdulkareem N, Soppa G, Jones S, Valencia O, Smelt J, Jahangiri M. Dilatation of the remaining aorta after aortic valve or aortic root replacement in patients with bicuspid aortic valve: a 5-year follow-up. Ann Thorac Surg. 2013;96:43-9.

20. Charitos EI, Stierle U, Petersen M, Mohamed SA, Hanke T, Schmidtke C, et al. The fate of the bicuspid valve aortopathy after aortic valve replacement. Eur.J Cardiothorac Surg. 2014;45:e128-35.

21. Regeer MV, Versteegh MI, Klautz RJ, Schalij MJ, Bax JJ, Marsan NA, et al. Effect of aortic valve replacement on aortic root dilatation rate in patients with bicuspid and tricuspid aortic valves. Ann Thorac Surg. 2016;102:1981-7.

22. Itagaki S, Chikwe JP, Chiang YP, Egorova NN, Adams DH. Long-term risk for aortic complications after aortic valve replacement in patients with bicuspid aortic valve versus Marfan syndrome. J Am Coll Cardiol. 2015;65:2363-9.

23. Park CB, Greason KL, Suri RM, Michelena HI, Schaff HV, Sundt TM III. Fate of nonreplaced sinuses of Valsalva in bicuspid aortic valve disease. J Thorac Cardiovasc Surg. 2011;142:278-84.

24. Milewski RK, Habertheuer A, Bavaria JE, Siki M, Szeto WY, Krause E, et al. Fate of remnant sinuses of Valsalva in patients with bicuspid and trileaflet valves undergoing aortic valve, ascending aorta, and aortic arch replacement. J Thorac Cardiovasc Surg. 2017;154:421-32.

25. Peterss S, Bhandari R, Rizzo JA, Fang H, Kuzmik GA, Ziganshin BA, et al. The aortic root: natural history after root-sparing ascending replacement in nonsyndromic aneurysmal patients. Ann Thorac Surg. 2017;103:828-33.

26. Feindel CM, Ouzounian M. To replace or not to replace mild to moderately dilated sinuses of Valsalva: when less is more. J Thorac Cardiovasc Surg. 2017;154:433-4.

27. Fazel SS, Mallidi HR, Lee RS, Sheehan MP, Liang D, Fleischman D, et al. The aortopathy of bicuspid aortic valve disease has distinctive patterns and usually involves the transverse aortic arch. J Thorac Cardiovasc Surg. 2008;135:901-7.

28. Hemli JM, R DeLaney ER, Dholakia KR, Perk D, Patel NC, Scheinerman SJ, et al. Rethinking the paradigm: modern approach to proximal aortic reconstruction demonstrates excellent outcomes. Heart Surg Forum. 2017;20:E092-7.

29. Park CB, Greason KL, Suri RM, Michelena HI, Schaff HV, Sundt TM III. Should the proximal arch be routinely replaced in patients with bicuspid aortic valve disease and ascending aortic aneurysm? J Thorac Cardiovasc Surg. 2011;142: 602-7.

30. Kang JW, Song HG, Yang DH, Baek S, Kim DH, Song JM, et al. Association between bicuspid aortic valve phenotype and patterns of valvular dysfunction and bicuspid aortopathy: comprehensive evaluation using MDCT and echocardiography. JACC Cardiovascular Imaging. 2013;6:150-61.

31. Habchi KM, Ashikhmina E, Vieira VM, Shahram JT, Isselbacher EM, Sundt TM III, et al. Association between bicuspid aortic valve morphotype and regional dilatation of the aortic root and trunk. Int J Cardiovasc Imaging. 2017;33:341-9.

32. Page M, Mongeon FP, Stevens LM, Souliere V, Khairy P, El-Hamamsy I. Aortic dilation rates in patients with biscuspid aortic valve: correlations with cusp fusion phenotype. J Heart Valve Dis. 2014;23:450-7.

33. Girdauskas E, Disha K, Rouman M, Espinoza A, Borger MA, Kuntze T. Aortic events after isolated aortic valve replacement for bicuspid aortic valve root phenotype: echocardiographic follow-up study. Eur J Cardiothorac Surg. 2015; 48:e71-6.

34. Della Corte A, Bancone C, Quarto C, Dialetto G, Covino FE, Scardone M, et al. Predictors of ascending aortic dilatation with bicuspid aortic valve: a wide spectrum of disease expression. Eur J Cardiothorac Surg. 2007;31:397-404.

Key Words: bicuspid aortic valve, aortic valve replacement, aortic root, aortopathy, aortic surgery

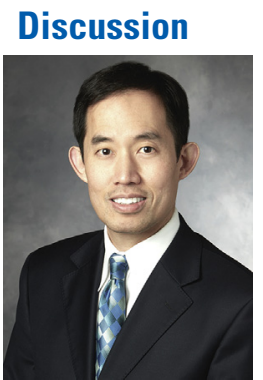

Dr Y. Joseph Woo (Stanford, Calif). I have no disclosures. Congratulations to you and your team for an excellent presentation and investigation.

Bicuspid aortopathy is a very complex topic. Beyond the genetic versus biomechanical etiologic hypotheses, one might also consider the at least $3 \times 3$ box of permutations of normal, stenotic, and regurgitant valves against normal, aneurysmal, and dissected aorta, and the 8 conditions or more generated, which might require intervention involving multiple forms of valvular repair or replacement and aortic replacement, and this is without considering aortic phenotypic variance.

This study elegantly focused on the natural history of, essentially, a mean normal-sized 3.6-cm aortic root and a mean normal-sized $3.3-\mathrm{cm}$ aortic arch in patients with bicuspid or tricuspid aortic valve disease and ascending aortic aneurysm, undergoing AVR and ascending aortic replacement and, occasionally, noncoronary sinus replacement. The group observed minimal growth of and, ostensibly, no need for reoperation for the unreplaced aorta.

I have 4 simple questions, with a primary goal of trying to give surgeons some practical guidance. What was the mean size of the ascending aorta that was replaced?

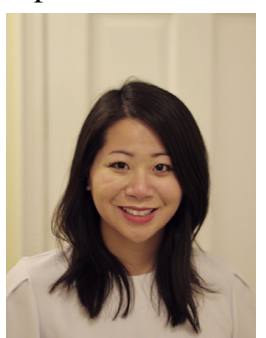

Dr Sonya K. Hui (Toronto, Ontario, Canada). The mean size of the ascending aorta in our entire study cohort was $4.6 \mathrm{~cm}$.

Dr Woo. Thank you. During the same time period, do you have a sense of how many patients underwent a full root replacement and was there a diameter threshold for the root to need to undergo that replacement?

Dr Hui. Thank you for your insightful questions. In terms of your first question, I can't speak to that; I wasn't a surgeon at our institution during that time.

Dr Woo. But you may be some day.

Dr Hui. Maybe some day. And then for your second question, sorry, can you repeat that?

Dr Woo. Is there basically a size threshold of the aortic root that would prompt the surgeons to replace all of the sinuses?

Dr Hui. At our institution, at the Toronto General Hospital, the threshold used for surgical intervention of replacing both the root or ascending aorta in patients who need to undergo an aortic valve replacement is $45 \mathrm{~mm}$ or $4.5 \mathrm{~cm}$.

Dr Woo. Was there a sense that there were perhaps a substantive number of patients who underwent a reoperation at 
your institution and underwent an aortic root replacement after an aortic valve replacement at another institution or your institution where the aorta was left alone?

Dr Hui. Again, I can't speak to the specifics of numbers for that, but that was a very insightful question. In speaking with my supervisor, that does happen at their institution.

Dr Woo. That does happen, even in Toronto.

Finally, have your findings guided your group's practice to become somewhat more conservative when approaching the aortic root?

Dr Hui. I would imagine so. I haven't specifically spoken to the team of staff surgeons since our manuscript was submitted, but I believe that would be the indication there. Dr Ouzounian could speak more specifically to that.

Dr Woo. Thank you. Well done.

Dr Faisal Bakaeen (Cleveland, Ohio). We have a quick comment from one of the authors.

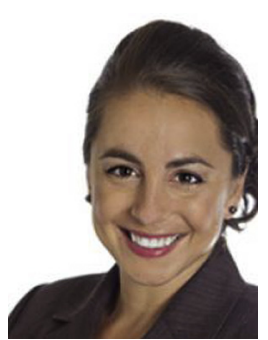

Dr Maral Ouzounian (Toronto, Ontario, Canada). Thank you, Dr Woo, for the discussion.

A few points. We do about 150 proximal aortic operations per year at our center; about 20 to 25 of them are valve-sparing roots, about 60 of them are Bentall operations. We do a fair number of redo operations. We do see redos for patients who have had isolated aortic valve replacements at our institution or another where the proximal aorta was left alone, but we very rarely see patients who have had AVR and their ascending aorta replaced who come back for isolated root aneurysm that was left alone. So that's very rare.

In terms of how this has changed our practice, bicuspid valve patients who don't have an aortic root phenotype, meaning they don't present with annuloaortic ectasia, regurgitant valves, and enlarged roots at the time of the index operation, most of the patients in this series are rather patients with stenotic valves, with normal or marginally enlarged roots and isolated ascending aneurysms. In those patients now we do feel more comfortable at leaving the root alone. If the posterior sinus or noncoronary sinus in the bicuspid valve patients is thin or the tissue quality is not good, we are quite aggressive at replacing with a patch only the posterior sinus, and if the coronary arteries are not displaced, we don't do a formal Bentall.

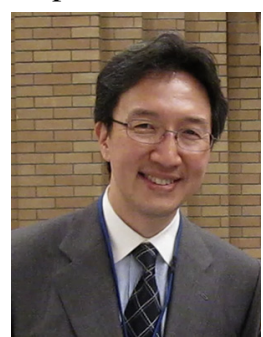

Dr Tohru Asai (Otsu, Japan). There are several different types, I mean, separate classifications of the bicuspid valve. Some regurgitant jet from the aortic valve are hitting a different part of the aorta. Is there any difference between this group classification and the enlargement speed of the aortic arch?

That is the only question.

Dr Hui. Within our study cohort or just in the literature?

Dr Asai. Or any incidence of dissection.

Dr Hui. There have been some recently published papers regarding the different bicuspid aortic valve phenotypes (ie, by left and right fusion or right noncoronary fusion, etc), and different shear stresses on the aortic wall, and there have been some statements made that perhaps different patterns of segmental aortopathy are related to the different bicuspid valve phenotypes. However, my understanding of the literature is that this isn't established yet. There have been some contradictory findings. Within our own study cohort, this was something of interest that we wanted to examine. Unfortunately we weren't able to find that data on enough of our study patients to perform a robust statistical analysis, so we weren't able to report if there was any difference in aortopathy between patients with different bicuspid aortic valve phenotypes. Those data were just not always reported in the operative reports.

Dr Bakaeen. A quick closing comment from Dr Woo.

Dr Woo. I would just commend our medical student on the stage and also note Dr Ouzounian's clinical skills, research productivity and, most importantly, her mentorship. 
TABLE E1. Imaging data according to modality

\begin{tabular}{|c|c|c|c|c|}
\hline & $\begin{array}{c}\text { Total number of } \\
\text { measurements }\end{array}$ & Echocardiography & CT & MRI \\
\hline Aortic root & 936 & $922(98.5)$ & $9(1.0)$ & $5(0.5)$ \\
\hline Aortic arch & 158 & $89(56.3)$ & $66(41.8)$ & $3(1.9)$ \\
\hline
\end{tabular}

Data are presented as $\mathrm{n}(\%)$ except where otherwise noted. $C T$, Computed tomography; MRI, magnetic resonance imaging.

TABLE E2. Details of cardiovascular reoperations

\begin{tabular}{|c|c|c|c|c|}
\hline Patient & Aortic valve & Procedure & Years postoperative & Indication for surgery \\
\hline 1 & BAV & TAVR & 13 & Failed aortic valve \\
\hline 2 & BAV & Bentall procedure & 15 & Failed aortic valve \\
\hline \multirow[t]{2}{*}{3} & BAV & Mitral valve replacement & 3 & Mitral regurgitation \\
\hline & & Mitral valve replacement, Bentall procedure & 10 & Failed prosthetic aortic valve and mitral valve \\
\hline 4 & BAV & $\begin{array}{l}\text { Aortic valve replacement, ventricular septal defect } \\
\text { repair }\end{array}$ & 6 & Endocarditis \\
\hline 5 & BAV & $\begin{array}{l}\text { Replacement of the aortic valve, ascending aorta and } \\
\text { noncoronary sinus }\end{array}$ & 10 & Failed aortic valve \\
\hline 6 & TAV & Aortic valve replacement, $\mathrm{CABG}$ & 6 & Failed aortic valve \\
\hline 7 & BAV & Bentall procedure & 9 & Aortic root abscess \\
\hline 8 & TAV & TAVR & 7 & Failed aortic valve \\
\hline 9 & BAV & $\begin{array}{l}\text { Mitral valve replacement, Bentall procedure, hemi- } \\
\text { arch replacement }\end{array}$ & 13 & Failed aortic valve \\
\hline 10 & BAV & Aortic valve replacement, patch & 2 & Failed aortic valve \\
\hline 11 & TAV & Bentall procedure & 8 & Failed aortic valve \\
\hline 12 & BAV & $\begin{array}{l}\text { Redo aortic valve replacement, mitral valve } \\
\text { replacement }\end{array}$ & 12 & Failed aortic valve \\
\hline 13 & TAV & Bentall procedure, mitral valve replacement & 12 & Failed aortic valve \\
\hline \multirow[t]{2}{*}{14} & BAV & Bentall procedure & 20 & Failed aortic valve \\
\hline & & Bentall procedure, arch replacement & 22 & $\begin{array}{l}\text { False aneurysm of left ventricular outflow tract, arch } \\
\text { aneurysm }\end{array}$ \\
\hline 15 & BAV & Bentall procedure & 12 & Failed aortic valve \\
\hline 16 & BAV & Bentall procedure, $\mathrm{CABG}$ & 7 & Failed aortic valve, coronary artery disease \\
\hline 17 & BAV & $\begin{array}{l}\text { Mitral valve repair, Bentall procedure, } \mathrm{CABG} \text {, left } \\
\text { coronary artery endarterectomy }\end{array}$ & 14 & $\begin{array}{l}\text { Failed aortic valve, mitral insufficiency, coronary } \\
\text { artery disease }\end{array}$ \\
\hline 18 & TAV & $\begin{array}{l}\text { Replacement of the aortic valve, noncoronary sinus } \\
\text { and mitral valve, CABG }\end{array}$ & 11 & $\begin{array}{l}\text { Failed aortic valve, mitral insufficiency, coronary } \\
\text { artery disease }\end{array}$ \\
\hline
\end{tabular}

$B A V$, Bicuspid aortic valve; $T A V R$, transcatheter aortic valve replacement; $T A V$, tricuspid aortic valve; $C A B G$, coronary artery bypass graft surgery. 